\title{
Effect of systemic arterial blood pressure on cerebral blood flow in intracranial hypertension
}

\author{
FRANK MATAKAS, GEORG EIBS, AND JOCHEN CUYPERS \\ From the Department of Neuropathology, Klinikum Steglitz, Freie Universität, \\ Berlin, W. Germany
}

\begin{abstract}
SYNOPSIS In five baboons and 11 cats cerebral ischaemia was produced either by inflating an epidural balloon and or by ligating major arteries supplying the brain. Fifteen of the animals developed intracranial hypertension after cerebral ischaemia. If ICP were high, but still significantly lower than MABP, elevation of MABP by noradrenaline infusions was accompanied by a proportional increase of ICP. However, the increase of ICP was lower than that of MABP so that CPP was raised. CBF measured by the ${ }^{133}$ Xenon clearance technique was significantly increased by arterial hypertension in eight cases. The proportional increase of CPP and CBF by elevation of arterial blood pressure was substantially greater, the lower ICP was immediately after ischaemia. There was no effect of MABP in cases in which ICP equalled MABP.
\end{abstract}

When brain oedema or brain swelling is combined with intracranial hypertension, the reduction of cerebral perfusion pressure (CPP) below $50 \mathrm{mmHg}$ may cause a reduction of cerebral blood flow (CBF) (Johnston et al., 1973). The possibility of re-establishing an optimal $\mathrm{CBF}$ in this situation is restricted. From a purely theoretical point of view CPP, defined as the difference between systemic arterial blood pressure and intracranial pressure (ICP) (Zwetnow, 1968), can be increased either by reducing ICP, or by increasing arterial blood pressure. However, in intracranial hypertension elevation of arterial pressure leads to a parallel increase of ICP (Langfitt et al., 1965; de Rougemont et al., 1972). The consequence of such an effect seems to be that elevation of blood pressure cannot improve CPP because of a proportional increase of ICP. In recent publications, however, it has been mentioned that the concomitant increase of ICP may be smaller than that of systemic blood pressure (Johnston et al., 1973; Shalit and Cotev, 1974). As a result, CPP may be increased by arterial hypertension. In a previous study we tried to elucidate this phenomenon by comparing experimental results to a mathematical model (Matakas et al., 1975). The present paper reports (Accepted 18 July 1975) on additional experiments concerning this phenomenon and tries to analyse the effect which an increase in CPP, induced by arterial hypertension, can have on CBF. The clinical importance of this problem is obvious: many patients with intracranial hypertension do have an elevated systemic blood pressure. A question is whether such an elevated systemic blood pressure is useful for the patient. If high arterial blood pressure has a positive effect on CBF, the question arises whether a normal blood pressure of patients with raised ICP may be allowed to be reduced-for instance, by narcotic drugs during operative procedures.

\section{METHODS}

Five baboons (17-25 kg) and 11 cats $(1.8-3.2 \mathrm{~kg})$ were anaesthetized with sodium pentobarbitone ( $25 \mathrm{mg} / \mathrm{kg}$ body weight). The animals were ventilated by means of endotracheal intubation. Blood gases were monitored with a Microastrup and maintained within normal values $\left(\mathrm{apO}_{2}: 85\right.$ to $100 \mathrm{mmHg}, \mathrm{apCO}_{2}$ : 35 to $40 \mathrm{mmHg}$ ). A Burster pressure transducer was placed epidurally over the left parietal lobe in order to measure epidural pressure (EDP). The electrocardiogram (ECG), EEG of both hemispheres, mean arterial blood pressure (MABP), and EDP were recorded continuously. Body temperature was 206 
regulated by means of a heating blanket ( 36.5 to $38.0^{\circ} \mathrm{C}$ ).

In the baboons, ICP was elevated by inflating an epidural balloon over the right parietal lobe with saline (ca. $20 \mathrm{ml}$ ). Inflation of the balloon was continued until EDP reached MABP. The period of artificial intracranial hypertension was extended for 20 minutes before deflating the balloon. In the cats, cerebral ischaemia was produced for 20 minutes by ligating the brachiocephalic trunk and the left subclavian artery after thoracotomy. During ligation of the arteries, trimetaphan (Arfonad) was administered so as to maintain MABP below $100 \mathrm{mmHg}$ and to prevent perfusion of the brain by anastomoses. Arterial hypertension was produced within the first hour after cerebral ischaemia by arterial infusion of noradrenaline $(400-700 \gamma / \mathrm{min})$. We tried to raise the arterial blood pressure to $200 \mathrm{mmHg}$ for 15 to 20 minutes.

CBF was measured by the Xenon clearance method before and after cerebral ischaemia and during the periods of low and high arterial blood pressure. The skin and temporal muscle of the left calvarium were reflected back. ${ }^{133} \mathrm{Xenon}(2.0 \mu \mathrm{Ci}$ baboon, $1.0 \mu \mathrm{Ci}$ cat $)$ dissolved in $1 \mathrm{ml}$ saline was injected into the left common carotid artery (the external carotid artery having been ligated in the baboons), and the Xenon clearance was measured over the left parietal lobe. The collimator had a diameter of $2 \mathrm{~cm}$. The clearance curves were analysed by a computer program (de Valois et al., 1970). In three baboons, carotid blood flow was additionally measured by an electromag- netic flow probe (diameter $3 \mathrm{~mm}$, Statham) attached to the left common carotid artery. After death, the brains were removed from the animals, fixed in formalin, and examined for tissue lesions.

\section{RESULTS}

During narcosis, all animals had a slight metabolic acidosis, with an arterial $\mathrm{pH}$ of about 7.25. The acidosis was corrected by small doses of intra-arterial bicarbonate. During cerebral ischaemia the EEG became isoelectric. A slow EEG activity returned in 10 to 20 minutes after the ischaemic state in only three baboons. In the baboons, MABP rose initially during cerebral compression to values of 130 to 220 $\mathrm{mmHg}$ (Cushing response), but declined gradually to 60 to $100 \mathrm{mmHg}$ by the end of artificial cerebral compression. The response of the blood pressure to noradrenaline was different in all animals. In some, a MABP of $200 \mathrm{mmHg}$ could be maintained for a longer period. In others blood pressure elevation was only small (Table).

$\mathrm{CBF}$ was measured in all animals two to three times before cerebral ischaemia occurred. The mean value of normal $\mathrm{CBF}$ in the baboons was $41 \pm 3.6 \mathrm{ml} / 100 \mathrm{~g} / \mathrm{min}$; in the cats it was $34 \pm 6.2$ $\mathrm{ml} / 100 \mathrm{~g} / \mathrm{min}$. The rather low level of normal $\mathrm{CBF}$ in the cats may have been caused by the fact that the ${ }^{133}$ Xenon was not restricted to

TABLE

CBF AFTER CEREBRAL ISCHAEMIA*

\begin{tabular}{|c|c|c|c|c|c|c|c|c|}
\hline \multirow[b]{2}{*}{ Group } & \multicolumn{4}{|c|}{$M A B P$ uninfluenced } & \multicolumn{4}{|c|}{$M A B P$ increased by noradrenaline } \\
\hline & $\begin{array}{c}M A B P \\
(m m H g)\end{array}$ & $\begin{array}{c}E D P \\
(m m H g)\end{array}$ & $\begin{array}{c}C P P \\
(m m H g)\end{array}$ & $\begin{array}{c}C B F \\
(\mathrm{ml} / 100 \mathrm{~g} \cdot \mathrm{min})\end{array}$ & $\begin{array}{c}M A B P \\
(m ! n H g)\end{array}$ & $\begin{array}{c}E D P \\
(m m H g)\end{array}$ & $\begin{array}{c}C P P \\
(m m H g)\end{array}$ & $\begin{array}{c}C B F \\
(\mathrm{ml} / 100 \mathrm{~g} \cdot \mathrm{min})\end{array}$ \\
\hline 1. Cat & 70 & 0 & 70 & 10 & 200 & 0 & 200 & 45 \\
\hline 2. Baboon & 85 & 5 & 80 & 16 & 130 & 30 & 100 & 26 \\
\hline Baboon & 70 & 0 & 70 & 8 & 190 & 30 & 160 & 54 \\
\hline Baboon & 105 & 0 & 105 & 10 & 180 & 40 & 140 & 31 \\
\hline Baboon & 85 & 0 & 85 & 5 & 200 & 20 & 180 & 23 \\
\hline Cat & 115 & 30 & 85 & 15 & 220 & 70 & 150 & 55 \\
\hline Cat & 40 & 25 & 15 & 20 & 115 & 85 & 30 & 33 \\
\hline Cat & 55 & 45 & 10 & 10 & 90 & 45 & 45 & 25 \\
\hline 3. Cat & 70 & 65 & 5 & 5 & 95 & 90 & 5 & 5 \\
\hline Cat & 75 & 60 & 15 & 10 & 150 & 135 & 15 & 15 \\
\hline 4. Baboon & 45 & 5 & 40 & 5 & 80 & 25 & 55 & 10 \\
\hline Cat & 110 & 20 & 90 & 10 & 120 & 10 & 110 & 10 \\
\hline Cat & 95 & 40 & 55 & 8 & 120 & 40 & 80 & 12 \\
\hline Cat & 75 & 25 & 50 & 21 & 200 & 70 & 130 & 23 \\
\hline Cat & 90 & 35 & 55 & 10 & 130 & 45 & 85 & 10 \\
\hline Cat & 90 & 70 & 20 & 18 & 100 & 65 & 35 & 20 \\
\hline
\end{tabular}

* All pressures are mean values observed during the time necessary for the ${ }^{133}$ Xenon clearance. 


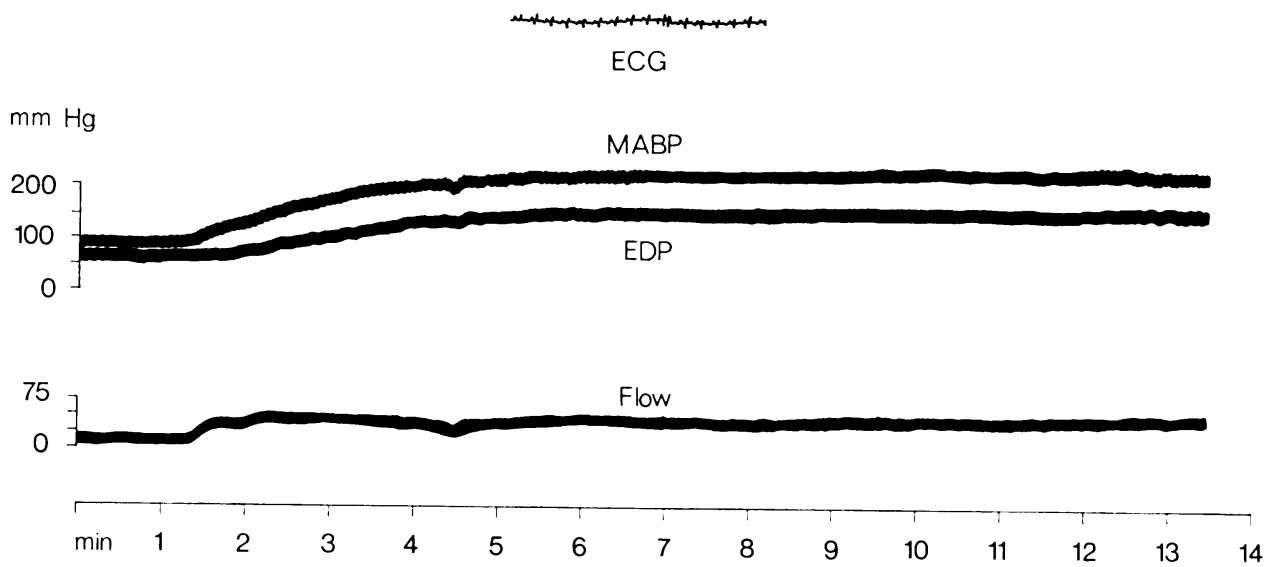

FIG. 1 Effect of arterial hypertension on EDP and carotid blood flow in a baboon (group 2) ca. 15 minutes after cerebral ischaemia of 20 minutes. During arterial hypertension, CPP and blood flow increase.

cerebral tissue only. However, it was found to be quite constant in repeated measurements.

$\mathrm{CBF}$ was reduced in all animals after cerebral ischaemia. The reduction of CBF was found to be much greater than that predicted by the perfusion pressure. The effect of elevated MABP and CPP was also different (Table). In one animal, EDP after ischaemia was low and showed no increase during arterial hypertension. CBF was markedly increased by arterial hypertension. In a second group of seven animals, arterial hypertension led to a proportional increase of EDP. This however, was lower than the increase in MABP which indicated that CPP had increased. There was a corresponding rise in CBF in this group (Fig. 1) which, according to the initial value, exceeded normal CBF in two cases. In a third group of two animals, EDP approached MABP. The increase of MABP caused a nearly equal rise in EDP, while perfusion pressure remained unchanged. CBF was not influenced significantly. In a fourth group of six animals, changes in CBF were either not significant or absent. In five of these animals arterial pressure rise was only small, so that EDP and CPP were only slightly increased.

Macroscopical investigation of the baboon brains showed small superficial haemorrhages at the site of balloon inflation. The superficial cortical layer in this region was found to be softened. No other brain tissue lesions were found to exist.

\section{DISCUSSION}

If primary elevation of CSF pressure is not taken into account, the development of intracranial hypertension is possible only if the intracranial tissue or the blood volume is increased. In the absence of autoregulation, ICP depends on intravascular pressure which, in the case of a reduced reserve space of the intracranial cavity, is transferred to brain tissue. This was first observed by Langfitt et al., (1965). They suggested that during or after severe cerebral hypoxia vasoparalysis occurs. As a result, elevation of MABP increases the intracranial blood volume which would raise intracranial pressure as soon as reserve space is used up. Thus, there may be three different effects of MABP on CPP (Matakas et al., 1975) (Fig. 2). If autoregulation be disturbed but the intracranial reserve space large, any increase of blood pressure increases CPP proportionally. Such was the case in the animals of group 1. Secondly, if ICP be increased but still significantly lower than arterial blood pressure, an increase in MABP is only partly transferred to brain tissue: CPP would therefore be increased by arterial hypertension, and CBF may also be increased. 

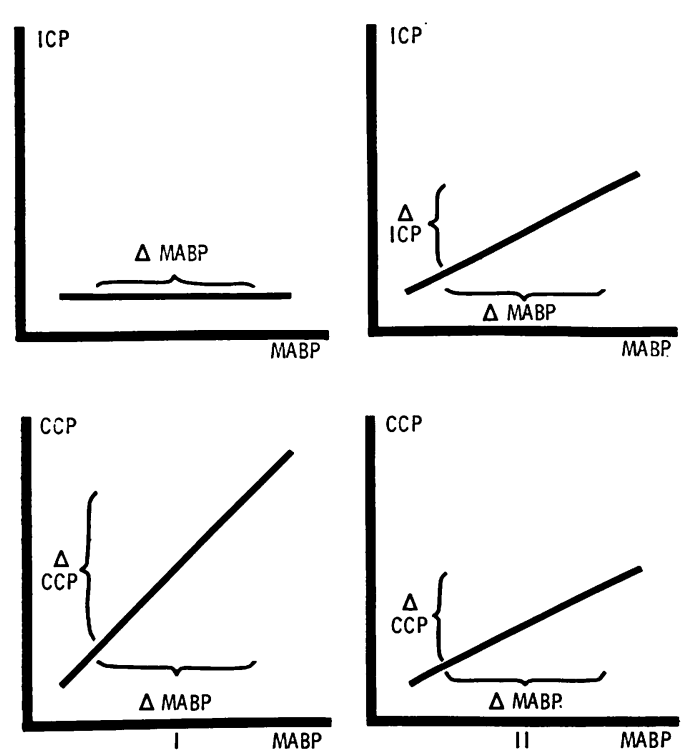

If, however, brain oedema or brain swelling be so extreme that ICP equals MABP, CPP is zero and independent of MABP. A change in MABP does not then alter CPP. This effect was observed in the third group of animals. (In the cats the increase of CBF measured during elevated arterial blood pressure may have been partly due to blood flow in extracranial tissue. However, since there was an equal result in baboons and cats, and as the collimator was so adjusted that the radioactivity of extracranial areas was minimized, the error is unlikely to be significant).

These experiments demonstrate that arterial hypertension may increase CBF in conditions of intracranial hypertension. However, the CBF measured after ischaemia was disproportionally low in relation to CPP. This observation is similar to the results of Johnston et al. (1973) who measured a CBF of less than $50 \mathrm{ml} / 100$ $\mathrm{g} / \mathrm{min}$ after cerebral ischaemia in monkeys, although CPP exceeded $100 \mathrm{mmHg}$. It is difficult to explain this phenomenon. From the experiments of Ames et al. (1968), we know that wide areas of the brain may show a no-reflow phenomenon after cerebral ischaemia. But if circulation is stopped in large areas of the brain after ischaemia this would not manifest itself by a reduction of the Xenon clearance because unperfused tissue areas do not receive Xenon and

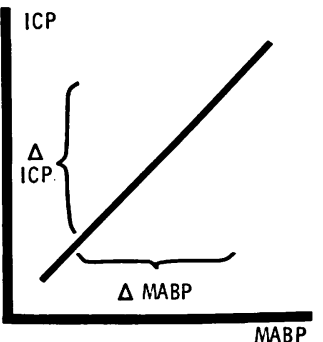

FIG. 2 Effect of arterial hypertension on ICP and CPP. It is supposed that autoregulation is impaired. (1) If ICP be normal, CPP is linear dependent on MABP. (2) If ICP be moderately elevated any increase in MABP is partly transferred to $I C P$. $C P P$ increases. (3) If ICP be equal to $M A B P$, a change in $M A B P$ has no effect on $C P P$.

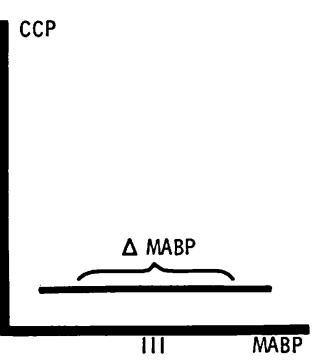

cannot therefore be detected by the Xenon clearance technique. A better explanation would be that, because of blood sludging during the ischaemic period (Hekmatpanah, 1970), the circulation in wide areas may be slowed down. This has also been assumed by Miller et al. (1973) who have observed a disproportionately low CBF despite increases in perfusion pressure during experimental brain compression with a balloon. Another explanation may be that CBF after ischaemia is impaired predominantly in the cerebral cortex, which may be an effect of the 'no reflow' (Cuypers and Matakas, 1974). CBF in the white matter, on the other hand, is normally much less than in cortical areas.

Shalit and Cotev (1974), in experiments similar to ours, have observed improvement of CPP and CBF during arterial hypertension in some animals but have concluded from their observations that an arterial pressure increase has no beneficial effect on CBF in conditions of brain swelling. Their hypothesis is that an arterial pressure rise increases ICP and that this increase in ICP would provoke a Cushing response-that is, a further increase in blood pressure. The blood pressure increase would again increase ICP, thus resulting in a vicious circle. This, in fact, is not the case, since the Cushing response is not triggered by the ICP, 
but by CBF or CPP (Sagawa et al., 1961; Matakas et al., 1971). If an increase in arterial pressure improves $\mathrm{CBF}$ and $\mathrm{CPP}$, the actual height of ICP has no significance. Shalit and Cotev (1974) were confused by the fact that the reduction of CPP and CBF which may occur during intracranial hypertension is the cause of arterial blood pressure increase and not the result. In their experiments, decrease of CPP and CBF might have been even greater if no Cushing response had occurred.

The results of this study might have some importance clinically even though they are not sufficient to draw definite conclusions about the optimal treatment of increased intracranial pressure. There are two ways in which arterial hypertension may be dangerous for a patient. The first is that, in cases in which intracranial pressure is caused by brain trauma, high blood pressure may aggravate brain oedema (Marshall et al., 1969). The second danger which may result from arterial hypertension is that elevated systemic blood pressure may produce haemorrhages in the presence of pressure gradients within the cranial cavity (Klintworth, 1968, Goodman and Becker, 1973). However, if brain oedema is not vasogenic, there is not the same danger of haemorrhage and a high arterial blood pressure may be beneficial because it guarantees an adequate $\mathrm{CBF}$.

We wish to thank Mrs I. Reich, Mrs B. Iser, and $\mathrm{Mr}$ Nowoitnik for their excellent technical assistance.

\section{REFERENCES}

Ames, A., Wright, R. L., Kowada, M., Thurston, J. M., and Majno, G. (1968). Cerebral ischemia 2: The no-reflow phenomenon. American Journal of Pathology, 52, 437-453.

Cuypers, J., and Matakas, F. (1974). The effect of postischemic hyperemia on intracranial pressure and the noreflow phenomenon. Acta Neuropathologica, 29, 73-84.
Goodmann, S. M., and Becker, D. P. (1973). Vascular pathology of the brain stem due to experimentally increased intracranial pressure: changes noted in the micro- and macrocirculation. Journal of Neurosurgery, 39, 601-609.

Hekmatpanah, J. (1970). Cerebral circulation and perfusion in experimental increased intracranial pressure. Journal of Neurosurgery, 32, 21-22.

Johnston, I. H., Rowan, J. O., Harper, A. M., and Jennett, W. B. (1973). Raised intracranial pressure and cerebral blood flow: 2. Supratentorial and intratentorial mass lesions in primates. Journal of Neurology, Neurosurgery, and Psychiatry, 36, 161-170.

Klintworth, G. K. (1968). Paratentorial grooving of human brains with particular reference to transtentorial herniation and the pathogenesis of secondary brain-stem hemorrhages. American Journal of Pathology, 53, 391-408.

Langfitt, T. W., Weinstein, J. D., and Kassell, N. F. (1965). Cerebral vasomotor paralysis produced by intracranial hypertension. Neurology (Minneap.), 15, 622-641.

Marshall, W. J. S., Jackson, J. L. F., and Langfitt, T. W. (1969). Brain swelling caused by trauma and arterial hypertension. Archives of Neurology, 21, 545-553.

Matakas, F., Leipert, M., and Franke, J. (1971). Cerebral blood flow during increased subarachnoid pressure. Acta Neurochirurgica, 25, 19-36.

Matakas, F., v. Waechter, R., Knüpling, R., and Potolicchio, S. J. (1975). Increase in cerebral perfusion pressure by arterial hypertension in brain swelling. Journal of Neurosurgery, 42, 282-289.

Miller, J. D., Stanek, A. E., and Langfitt, T. W. (1973). Cerebral blood flow regulation during experimental brain compression. Journal of Neurosurgery, 39, 186-196.

Rougemont, de, J., Barge, M., and Benabid, A. L. (1972). Correlative study of intracranial and systemic arterial pressures in neurosurgical patients. In Intracranial Pressure, pp. 232-238. Edited by M. Brock, and H. Dietz. Springer: Berlin.

Sagawa, K., Ross, J. M., and Guyton, A. C. (1961). Quantitation of cerebral ischemic pressure response in dogs. American Journal of Physiology, 200, 1164-1168.

Shalit, M. N., and Cotev, S. (1974). Interrelationship between blood pressure and regional cerebral blood flow in experimental intracranial hypertension. Journal of Neurosurgery, 40, 594-602.

Valois, de, J. C., Smith, J., and Peperkamp, J. P. C. (1970). A computer program for the determination of cerebral blood flow using the $\mathrm{Kr}-85$ or Xe-133 intraarterial injection method. Progress in Brain Research, 33, 231-241.

Zwetnow, N. N. (1968). CBF autoregulation to blood pressure and intracranial pressure variations. Scandinavian Journal of Laboratory and Clinical Investigation, suppl. 102.V: A. 